\title{
Connections between Artistic Practice and Experiences in Nature: Considerations for how Art Education Can Engender Ecological Awareness
}

\author{
Zuzana Vasko, Simon Fraser University \\ zvasko@sfu.ca
}

\begin{abstract}
Experiences of artistic engagement share many commonalities with those of being immersed in the natural world. Both experiences call upon sense perception, embodiment, the imagination, the emotions, as well as a sense of beauty and the spiritual implications it can bring. These commonalities are of value to education in their own regard, yet when the arts are explored and experienced in relation to the natural world, they have the potential to form fertile ground in which the seeds of a personally involved and deep ecological awareness can grow.
\end{abstract}

Keywords: Eco-art Education; Aesthetic Experience; Phenomenological Approaches to Art; Ecological Awareness; Holistic Education

$\mathrm{S}$ tephen Jay Gould (1991) proposes that an emotional bond with the natural world is essential if we are to protect it, "for we will not fight to save what we do not love" (as cited in Orr, 2004 , p. 43). Art making and aesthetic engagement have their own special way of inviting emotive relations with the subject matter they explore, and art education can thus be a subtle yet powerful context within which to engender the kind of emotional bond Gould speaks of — not just for the sake of natural ecologies, but for our own enrichment as beings who need a sense of belonging and connection to place, environs and other life forms. Contemporary art has traditionally addressed mostly human concerns, part of which has been a sense of alienation from our social and physical contexts. Yet more recently, environmental issues have become a relevant concern addressed by artists who seek to re-examine the various ways in which we relate - for better or for worse - to the natural world. Correspondingly, ecological art education has established itself as a field in its own right (Inwood, 2008) seeking both to critique the paradigms at the root environmental damage (Anderson \& Guyas, 2012) as well as to engender more affirmative and holistic relations between children and the natural world (Van Boeckel, 2009).

I would like to consider here some pertinent characteristics that the experiences of art practice and immersion in nature have in common, particularly with regard to what they call upon and address in us as engaged participants. By looking at the phenomenological nature of encounters with art and those with nature, we can consider the ways in which these experiences might work together in a kind of mutual augmentation. In homage to the work of Gregory Bateson, Jan Van Boeckel (2011) explores Bateson's proposal that "when we find meaning in art, our thinking is most in sync with nature" (p. 1). In these contexts, the forms of communication we find ourselves involved in are not easily defined, interconnected as they are with possibilities beyond ourselves that we cannot always explain. It is this synchronisation - the common ground shared by these two areas - that I would like to consider here in its various facets, in an endeavour to 
better understand some foundations of arts-based environmental awareness and the valuable ramifications it can have.

\section{Primacy}

A fundamental aspect shared by these forms of engagement is that both the natural world and the arts have been with us since the beginning of our humanity: they have shaped who we are as a species. Ellen Dissanayake (1995) observes that the arts and culture have been a necessary part of our evolution as human beings, and that people of all ethnicities the world over have always engaged with the arts in some way. She addresses "a core human nature that was evolved to require aesthetic and spiritual satisfactions,"'(p. 3) and claims that because of the pleasure the arts give us, because they are so emotionally satisfying, and because the cultural connections they enable us to form have been significant to our survival, our need for them is inherently biological. In her view, the impulse to create and 'make special' precedes the habits of intellect and conceptualisation so esteemed in our current times — that often harm the more primal inclination to get caught up in acts of creation.

As human beings we have always required beauty and meaning; we have sought means of transformation that help us make spiritual sense of our predicaments and helps us authenticate our place in the world. In tribal cultures this was often done collectively through ritual (Cajete 1994, Dissanayake, 1995). In contemporary times, we tend to seek forms of meaning through more individual preferences and choices, given the vast array of arts and culture options in urban centres and through mass media. The act of creation has also acquired strong associations with individual expression. Our contemporary ideas of art, often seen as decoration or objects of aesthetic beauty in an edifying sense, or as means creating a personal statement or raising awareness of social issues, are rather different from indigenous forms of art, which were integral to spiritual rituals and more pertinent to the very basics of life (Dissanayake, 1995; London, 1989). Yet whether the impulse is to express something, to explore and bring awareness to new perspectives, to enhance ourselves or our objects and experiences, to find a form of transcendence or even just to gain momentary escape, the desire for art remains inherent to being human.

It also seems self-evident that the natural world has always been an essential part of our lives, even if it may seem notably less so in our industrialised times. Cultures evolved from the geographies and ecologies that were home to them. For the many generations preceding ours, reciprocal relationships between humanity and the rest of the natural world were a given (Abram, 1997). Yet even in our current times, we are affected and shaped by the landscape that gives us home. One's consciousness is subtly, yet palpably, different when one is on the rainy, mountainous, wooded west coast than when one is on flat prairie with large open skies above. There is also the deep need that we feel to be around nature. Theodore Roszak (2010) argues that the field of psychology needs to acknowledge the connection between the human psyche and the natural environment - what he calls an ecological unconscious - that on a fundamental level, the "human psyche is grafted to the planet out of which we evolved." Edward O. Wilson's concept of 'biophilia' holds that we have a natural, likely even a biological, affinity toward nature, an "urge to affiliate with other forms of life," (as cited in Louv, 2005, p. 43). Research around this theory shows that as humans we respond very positively to natural landscapes, yet my sense is that this research shows what most of us already know - that our attraction to various forms of nature is often primal, inherent and involuntary, and not something we can put down to social conditioning.

\section{Beauty and Pleasure}


In looking at how beauty is a kind of essential cornerstone affecting our experiences of both nature and the arts, Immanuel Kant's ideas on aesthetics as proposed in The Critique of Judgement (1790) are helpful, and not only because they address aesthetic beauty in both these areas. ${ }^{i}$ His concept of free beauty found that aesthetic enjoyment occurs when things are perceived in a certain way, most notably without the interference of concepts or rules. There is also his idea of disinterestedness, where we put aside self-interest, appreciating the object of our contemplation for its own sake rather than as something that might serve $u s$. In his consideration of this notion, Stuart Richmond (2004) uses the example of viewing an old-growth forest, and describes how one might respond to it in the way Kant proposes: without concepts or self-interest, allowing the eyes, mind, and imagination to roam freely, taking in the qualities of colour and form, the imagination being at free play with our other faculties. In my mind, that is how a child might view it, with a sensuous primacy and freshness free of conceptual filters.

In contrast, "seeing an old growth forest in terms of its botanical properties or cash value, for example," (p. 4) are clearly concept-governed perspectives, the latter being one of self-interest and personal gain; both would rule out the possibility of free beauty on a more purely aesthetic level. Yet the idea of being completely concept-free is not always workable. Richmond (2004) describes how our experience of nature can be augmented by cognitive knowledge; indeed, a fuller appreciation often involves being able to distinguish different types of birds, flowers and trees, appreciating, for example how an "oak forest is different from one of pine" and that "it is a source of much delight to be able to identify such things" (p. 81). My own immersion in west coast forests became more complete once I came to know: this is salmonberry, that is salal; these are licorice ferns clinging to the cliff; those hauntingly lovely mosses hanging from tree branches are old man's beard. Richmond (2004) finds that as it is, Kant's concept of free beauty can succeed "only by losing touch with life" (p. 82). In the context of contemporary culture, so shot through with information, concepts and labels, and where it is difficult to escape human valuations and interpretations of everything, the idea of free beauty may seem even less viable.

Yet, perhaps for these very reasons, a focus on the more sensuous and primal aspects of perception - liberated, even if only for a brief moment, from socially formed concepts — also seems that much more important. There is also something particularly significant about the idea of disinterested pleasure as it applies to our experiences of art - and particularly to those of nature, since nature can also be a realm to which we turn for our practical needs of survival and material gain. Experiences that are relatively disinterested in this regard make room for the appreciation of beauty. Kant (1790) also proposed the notion of purposiveness without a purpose, which is particularly fitting here: a form has a look of rightness about it as if it were meant for a function, yet the rightness is actually that way in itself, rather than with an aim of utility. This is valuable if we want to appreciate things for what they are, in and of themselves. I love how Iris Murdoch (1971) puts it when she says that good art "teaches us how things can be looked at and loved, without being seized and used" (p. 64). While her statement here pertains to art, it can be equally so with nature; indeed she uses similar examples from the natural world. The experience of beauty is described by Richmond (2004) as "a sense of pleasure and well-being that we cannot help wanting"; he states Plato's observation that it "is the only visible quality that inspires love" (p. 78). In many respects it is essential that we $d o$ find nature beautiful in this freer sense if we are to regard it as worthy of being close to, and of protecting. Thus, the surrender to a quality that inspires love is in itself a valuable relational experience.

Kant (1790) also grappled with the intersubjective nature of beauty, believing that while there are subjective differences in judgement between individuals, there are still many things we 
would agree upon as beautiful. In that regard, he aimed to show that the features of beauty go beyond mere personal taste - that they can be seen as inherent in the phenomena themselves. Cynthia Freeland (2001) interprets his views by saying that while beauty cannot be objective, there is something about it that is grounded in the real world (pp. 9-14). To me, there has always been something heartening about this idea, despite encounters with varying and conflicting perceptions of what is considered beautiful, particularly in a culture that slips easily into relativism. I also find it especially worthwhile when it comes to our feelings toward nature: appreciating that it has inherent qualities that might move us, albeit in slightly different ways for everyone, seems a much more valuable ethic than the facile dismissal that while you find this beautiful, I do not. The experience of beauty has life-affirming qualities, and is in many respects, a necessary curative to our means-ends, techno-driven and fast-paced economy. Beauty's qualities are inherently relational, connecting us to the life both around, and within, ourselves.

I would like to take a bit further the idea of things being loved and held as special for their own sake, free of thoughts of usefulness or personal gain. In a secular society, there is little we might agree upon as being sacred; there is certainly not much that would remain so across time and cultures. Yet Margaret Somerville (2006) takes on an exploration of what we might regard as the 'secular sacred' - a means of finding a shared ethics without relying on religious spheres. It is interesting to me how her examination of what might be meant by the secular sacred echoes the ideas around beauty I've been considering, particularly with reference to Kant (1790). That which we consider sacred, Somerville (2006) says, "must have some kind of authenticity apart from utility, personal preference, or a desire that it be such — it must have 'a life of its own'" (p. 54). She speaks of intrinsic qualities, and of an inherent integrity which we agree needs to stay intact; in other words, we don't 'do' things to it or manipulate it simply because we can. In considering how we experience the sacred, she mentions examples to be found in the natural world and in "beautiful music and art," then describes:

A sense of the sacred is present when we feel awe at being alive and conscious of the beauty, world, and life around us. It is no accident that we often find that experience in nature (p. 59).

It interests me that her examples of what we might agree upon as experiences of the sacred are the arts and nature. It may be that a sense of the sacred has become somewhat neglected, even devalued and mistrusted in the economically-driven thinking of our time. Yet ideas of intrinsic value, appreciation of beauty and the sacred fulfill deep human needs.

Echoing Plato's observation of beauty being the only visible quality that inspires love, Sappho poignantly observes that one finds the most beauty in "whatever one loves" (Sartwell, 2004 , p. vii). It seems to be somewhat of a cycle then: we love what we find beautiful, and also find beautiful the entities we love. What one loves, or learns to love in life, can be deeply personal and varied, and is a very important idea in its own right, especially with regard to ecological preservation. My observation is that when it comes to beauty, it is often to forms of art or to nature that we turn to fulfil this need. And if beauty and love are thus connected, it appears there would then be great ethical value in finding beauty in nature, since it is out of a sense of love, more than anything else, that we are impelled to protect it.

\section{Sense Perception}

Encounters with the natural world and engagement in art both involve our senses in such essential and necessary ways that the entire experience sources from what our senses directly take in. We are not being given facts, information or second-hand knowledge; rather, we absorb things 
in a more primal, direct and subtle way, and we absorb them for ourselves. The nature of the experience is visceral and personal. Seeing or hearing something for oneself is a most immediate way of gaining knowledge, and a sense of knowing, as opposed to gaining knowledge in an academic sense, is gained from looking and listening sensitively, sometimes repeatedly, until what we see and hear is internalised, becoming our own. ${ }^{\text {ii }}$ Trusting our senses as a form of knowing seems almost to go against the current in a context where mainstream systems of learning are becoming increasingly reliant on texts and electronic media. While it might be possible to argue that greater quantities of knowledge are available to us through information and through the telling of others, it is often at the expense of sensory richness and depth, and ultimately a loss to the very quality of our lived experience. In expressing concerns about the kind of know-it-all culture that information technology has helped build, Louv (2005) observes how it has come at the price of the richness and depth offered us by lived sensuous experience (p. 54-69).

While Louv (2005) speaks of experiences in nature, London (2003) speaks of the importance of encountering things first hand, through the practice of art, as a means to "break through the myriad veils" of indirect learning (p. 60). He also remarks how artists take the life and wisdom of the senses seriously, as the senses reveal to us things that matter (pp. 80-87). In artistic practice, this is often doubly true, occurring not only with regard to what is noticed and being depicted in subject matter from the world around us, but also in the physical rendering of qualities of form, colour, rhythm and tone in the work one makes. Biologist Rachel Carson (1956), seeking to instil a life-long sense of wonder in a child through encounters with nature, emphasizes coming to know the world through open and receptive senses, and values seeing and listening far above the ability to identify certain birds or plants. Carson feels all the senses to be valuable as means of knowing, and suggests the conscious cultivation of smell, touch and, in the example that follows, hearing.

No child should grow up unaware of the dawn chorus of the birds in spring. He will never forget the experience of a specially planned early rising and going out in the predawn darkness. The first voices are heard before daybreak. It is easy to pick out these first solitary singers... The chorus picks up volume as more and more robins join in, contributing a fierce rhythm of their own that soon becomes dominant in the wild medley of voices. In that dawn chorus one hears the throb of life itself (p. 68).

An augmented life of the senses is essential if we want to let in the more evocative aspects of nature, and the senses need to be opened, honed and receptive if the voices and sights of nature are to affect us with some depth. Artist-educator Jan van Boeckel (2009) speaks of the need to open our senses in ways precisely such as this, citing art as a means to increase sensuous receptivity, particularly as a countermeasure to the technological overstimulation that tends to decrease children's sensitivity to the subtleties of nature.

Bringing the phenomenological work of Merleau-Ponty to bear on ecological concerns, David Abram (1997) describes how the immediacy of perception, as well as its subjective nature, brings us closer to things: "In the act of perception... I enter into a sympathetic relation with the perceived" (p. 54). We are in the experience, and things unfold for us "as we spontaneously experience them, prior to all our conceptualizations and definitions." He observes how MerleauPonty writes of "perceived things as entities, of sensible qualities as powers, and of the sensible itself as a field of animate presences" (p. 56). To distance ourselves from our senses, then, is to remove ourselves from relations with things. To repress sensual involvement is to become detached, in effect to "block our perceptual reciprocity" with other beings (p. 56). It is clear that he speaks here not of superficial surveillance - the kind we might do when looking for a specific 
answer, or when we simply glance with unseeing eyes — but rather something much more actively participatory and immersed, involving interactive openness and a willingness to surrender to what the entities around us might emanate. It is the kind of engagement that involves us personally. It makes sense then, why it is no doubt easier to make decisions to clear forests and land when that is done from an impersonal distance, looking mostly at facts, figures and maps with a view to achieve a human-serving plan. The kind of personal, sensuous, immersion that artistic engagement calls upon invites us instead into relationship with our surroundings.

\section{Embodiment}

Intelligence, emotions and forms of knowing reside not only in the mind, but also in the heart, the feet, the hands, the gut and the spine; they are within the comportment of our bodies as they manoeuvre themselves through various spaces and contexts, through the feel of various situations. We know of muscle memory as a kinesthetic term, yet the knowledge in our muscles is not merely the result of mechanically repeated positions and movements. In an article I once read where musician Tom Waites describes his song-writing process at the piano, he speaks of the fingers as being ahead of the mind in intelligence. The skills and knowledge that are called upon in the arts reside in eyes and ears, in muscle and sinew, and sometimes, in parts of ourselves not easily located. Significant creative decisions such as how to manoeuvre the feel and tone of a work are not made altogether cognitively, but rely also upon something deeper down, often guided by an intuitive gut sense. This kind of intelligence is also brought to life when we absorb and respond to works of art. The mind might enjoy being at 'free play' as Kant (1790) would say, and also make valuable personal and cognitive connections, yet, "at least some of the intense pleasures of aesthetic experience are insistently bodily," as Dissayake asserts (p. 28), maintaining that the physicality of the experience is necessarily relevant.

Something very similar occurs when we allow ourselves to be absorbed in nature. Here, our bodies are in it: whether we hike through a wild place or observe its forms more serenely, sensations are felt in our whole selves. It is the feel of sun on our skin, the crunch of gravel or the crack of sticks under our feet, the shelter of shadow, or the quiver of adrenalin through our veins at the sight of an unexpected creature crossing our paths that makes the experience what it is. It is the ache of muscles not normally used in an urban setting, the catch deep in the breath when we behold a vista that takes us away from the mundane. Yet while these bodily experiences are individually felt within, they are in direct relation to that which surrounds us, to the terrain, the temperature, the light, the insects and calls in the air. In Abram's (1997) words, "The body is that mysterious and multifaceted phenomenon that seems to always accompany one's awareness and indeed to be the very location of one's awareness within the field of appearances" (p. 37). He speaks of a "carnal resonance" that is necessary to phenomenal knowing, particularly as it relates to other forms of being in our ecologies. And this is why bodily engagement is significant - as a place of perception, emotion and intelligence, the sensing, feeling and knowing body is necessarily in relation to other bodies around it:

To acknowledge the life of the body and to affirm our solidarity with this physical form, is to acknowledge our existence as one of the earth's animals, and so to remember and rejuvenate the organic basis of our thoughts and our intelligence (Abram, 1997, p. 47). It is being physically present that enables us to be part of the phenomenal world. This embodied relatedness is also something I feel when I am drawing the contours of a tree, when I stand in front of a painting that speaks to me, or when the composition of an image somehow feels just right. There, too, the carnal resonance is felt. 


\section{Emotion}

Tolstoy claimed that the main task of an artist was to evoke and communicate feelings (Freeland, 2001, p. 155). While there are other (notably Western) theories of art that focus more emphatically on form, or those that are more cognitively oriented toward expressing ideas or provoking social awareness, many would say that ideally a work of art includes considerations of all of these, and that most especially it needs to express well what it aims to communicate. Susanne Langer (1953) claims that when we understand a work of art, it is the feeling within and behind it that we grasp, and that we often judge a work on how truthfully it expresses that feeling (pp 374381). In all the arts, we often deem a work by how well it conveys a certain emotional truth: in a story, a novel, a film, even in an image, we allow for all kinds of physical realities not possible in our real lives, yet we require emotional situations - even those very different from our own - to be portrayed or symbolised with honesty if we are to be convinced or moved. While Langer uses the term 'feeling' in a broad sense, encompassing everything from physical sensation to "the most complex emotions, intellectual tensions or the steady feeling-tones of a conscious human life," (as cited in Freeland, p. 160-161) her view is that the expression of feeling is central to art. Recalling Gould's emphasis on an emotional bond with nature and other forms of life, and this realm of feeling inhabited by art is provides rich soil where personal connection to the natural world can take root and grow.

One might not necessarily think of involvement in the outdoors as an invitation to look into matters of emotion in ways we may take for granted in the arts. Yet my experience and the experiences I have heard of from others tell me that in the natural world we are more likely to release the guards and masks we maintain in more urban settings. Somehow, nature gives us permission to be more truly ourselves, as we are released for a moment from the role-oriented messages that are inevitably part of an urban environment. During a presentation I did with colleagues on educating children in the outdoors, a teacher participant raised the concern of how to handle matters if a child's experience in the woods gave rise to strong emotional feelings. None of us were surprised by this question, and we agreed it was a valid concern: while we often think of retreating to nature as a balm to sooth us, it can also be an experience where the things deeper within us are uncovered and rise to the surface.

We also tend to have strong emotions in relation to particular places. I am heartened by David Orr's (2004) claim that we are at a time when these emotions (notably, those of love) need to take precedence over more scientific forms of knowledge (p. 43-44). Traditionally, in the sciences, feeling and emotion have been disregarded and viewed as suspect. Yet life and its processes are coloured by matters of feeling, and Orr's claim is that addressing these needs to be part of the responsibility that goes with knowledge, particularly if education is to prepare one to take part in projects that affect the environment, as almost all human endeavours tend to do. I feel strongly that our awareness of nature, environment and ecology needs to take hold on an emotional level. Bill McGibben (2005) puts it incisively when he says that we are faced with a curious paradox:

One species, ours, has by itself in the course of a couple of generations managed to powerfully raise the temperature of an entire planet, to knock its most basic systems out of kilter. But oddly, though we know about it, we don't know about it. It hasn't registered in our gut; it isn't part of our culture. Where are the books? The poems? The plays? The goddamn operas? Compare it to, say, the horror of AIDS in the last two decades, which has produced a staggering outpouring of art that, in turn, has had real political effect. I 
mean, when people someday look back on our moment, the single most significant item will doubtless be the sudden spiking temperature. But they'll have a hell of a time figuring out what it meant to us (para 1).

McGibben wrote this in 2005; in more recent years, many artists have taken up the concern of ecological issues. It seems to me critical that our younger generation come closer to their natural ecologies in similarly affective ways. While the larger (more concerning and perhaps more frightening) environmental issues are best reserved for more mature students, the gut-level connection that McGibben speaks of is immensely significant with younger children as well, though at this age it needs to be done in more positive and life-affirming ways. Innocence and love are gut-level sensations also. The arts help us encounter and address these matters in ways that are sincere, conscious, in-depth and, where appropriate, critical. Art can also be a means of helping young people engage honestly and effectively with the daunting environmental issues they hear of too often.

\section{Affect and Imagination}

We naturally accept that the arts offer us room for the subjective, the affective and for the imagination, yet less commonly are these qualities associated with learning about ecology and the natural world. In schools, studies of nature are traditionally taught within a scientific framework. Yet I would argue that the affective and imaginative aspects offered us by the natural world are substantial and need to be explored in greater depth and breadth. Emily Brady (2003) views the imagination as a necessary complement to scientific perspectives to environmental knowledge, even as a corrective to what might be overly cognitive approaches (pp. 158-161). She suggests that various forms of knowing need to work in complement with each other: imagining well - which can be done with the aid of scientific knowledge - is valuable in that it enables us to expand out from, as well as return us back to, the qualities of what we are seeing. Yuriko Saito (2007) concurs with this view, lamenting that "the study of nature is concerned primarily with scientific education, with little emphasis on promoting aesthetic appreciation" (p. 84). In the context of coming to know the natural world (whether with regard to organisms and ecology or in a more personal sense), the imagination does two important things: it allows entities to come alive for us in a way that enables us to relate to them, which then puts us closer to a place of empathy.

The imagination is also very responsive to nature. The open-ended and diverse qualities of natural environments provide wonderful fodder for discovery and creativity. Louv (2005) mentions several studies where children spending time in green spaces engage in play that is far richer in inventiveness, make-believe and sustained stories than those who play in built playgrounds. He cites architect Simon Nicholson, who attributes this to what he calls a theory of 'loose-parts,' where the various elements of the outdoors - trees, rocks, streams - engage the senses and the body in a way that can be infinitely and openly combined (p. 85-87). My experiences of taking children into fields and woods is that they interact with natural places differently than adults do: rather than hike through them, for example, they like to be 'in' them, seeking out places to crawl into, imagining stories of haunted and forbidden forests and the creatures that might live there. My son once spent part of an afternoon exploring a small creek, imagining himself in miniature in the context of its various features and topographies.

This sense of imaginative freedom in nature is on offer for all of us, not just for children. I find Brady (2003) puts it well in her description of Kant's perspective of how the appreciation of nature has inherent creative aspects: 
For Kant, the imagination is central in aesthetic judgements of nature. It frees the mind from the constraints of intellectual and practical interests and enables a play of associations and creative reflection in relation to nature's qualities (p. 147).

The physical openness offered by natural places, as well as the release for a moment from urban structures and ideas of how things should be, somehow allows for the exploration of new perspectives. The idea of loose parts and that things can be combined in fresh ways would apply to the adult imagination also, bringing about the sense of play Kant speaks of here, in the way thought and perception come together.

Nature has also been the subject of much drawing, painting and photography throughout our history. Looking back to early human life, it can also be argued, as David Orr (2004) has done, that our inspiration from the natural world was what brought about our desire to be expressive to sing and dance, to create images and meaningful rituals - in the first place (p. 51).

\section{Impediments}

There is another important aspect shared by conscious involvement with the natural world and with aesthetic engagement: both these experiences can be impeded, and even dismissed, by certain facets of our everyday experience - facets all too common for most of us. The fast pace of our daily lives, the pressures to accomplish much within a certain time, preoccupation with digital devices and with the instrumental bottom line of many endeavours: all of these can lead to a general lack of being present and attentive to the world around us, and, also, within us. If we too often find ourselves in a constant state of fast-forward, there is much in our lives we miss out on, including the ability to be creative (Honore, 2004). Time pressures, distractions and lack of presence also impede any deeper sense of the kind of aesthetic involvement that affects us personally. Perhaps this points to one of the most substantial values of aesthetic education and of time spent with the natural world: the acts of slowing down and of taking notice, of being present enough to observe nuance and take seriously the affective dimensions of things around us, of taking time to absorb and reflect, of stilling the self and being free for a time of pressures and preoccupations - these have ethical ramifications of no small significance.

\section{Conclusion}

That these two forms of experience share much in common is tremendously valuable for both art education and environmental education, particularly if the latter seeks to create personal connections with ecologies close to home. To me, a particularly valuable element of art education is that it can be a means to a deeper and more appreciative awareness of our physical environs and communities. Maxine Greene (1995) proposed that the arts encourage us to notice what there is to be noticed. Whether our aim is to build a sense of belonging with the physical places we inhabit, to come to know (and possibly love) natural areas and life forms for their own sake, to address questions about how we relate to environment and other forms of life, or to voice concerns for their well-being - and, in consequence - our own, this practice of noticing through the arts invites a feelingful sense of connectedness to our natural ecologies and environments. 


\section{References}

Abram, D. (1997). Spell of the sensuous: Perception and language in a more-than-human world. New York: Vintage Books.

Anderson, T. \& Guyas, A.S. (2012). Earth education, interbeing and deep ecology. Studies in Art Education 53(3), 223-245.

Brady, E. (2003). Aesthetics of the natural environment. Edinburgh University Press.

Cajete, G. (1994). Look to the mountain: An ecology of indigenous education. Durango, Colorado: Kivaki Press.

Carson, R. (1956). The sense of wonder. New York: Harper \& Row.

Dissanayake, E. (1995). Homo aestheticus: Where art comes from and why. Seattle: University of Washington Press.

Eisner, E. (2002). The arts and the creation of mind. New Haven: Yale University Press.

Freeland, C. (2001) But is it art? An introduction to art theory. New York: Oxford University Press,

Inwood, H. (2008). Mapping eco-art education. Canadian Review of Art Education: Research and Issues, 334(1), 57-72.

Kant, I. (1790/1982). The critique of judgement, (J.C. Meredith Trans.). Oxford: Clarendon Press.

Langer, S. (1953). Feeling and form: A theory of art. New York: Charles Scribner's Sons.

London, P (1989). No more secondhand art: Awakening the artist within. Boston: Shambala Publications.

London, P. (2003). Drawing closer to nature: Making art in dialogue with the natural world Boston: Shambala Publications.

Louv, R. (2005). Last child in the woods. Chapel Hill, North Carolina: Algonquin Books

McGibben, B. (2005, April). What the warming world needs now is art, sweet art. Grist Magazine, April 2005. Retrieved from: http:/grist.org/article/mckibben-imagine/

Murdoch, I. (1971). The sovereignty of good. London: Routledge and Kegan Paul.

Greene, M. (1995). Releasing the imagination: Essays on education, the arts and social change. San Francisco: Jossey-Bass. 
Honore. C. (2004), In praise of slow: How a worldwide movement is challenging the culture of speed. Toronto: A. A. Knopf Canada.

Richmond, S (2004). Remembering beauty: Reflections of Kant and Cartier-Bresson for aspiring photographers. The Journal of Aesthetic Education, 38 (1), 78-88.

Roszak, T. (posted 2010). Towards an eco-psychology. Thinking Allowed. DVD (with Mishlove, D.) http://www.thinkingallowed.com/2troszak.html

Sartwell, C. (2004). Six names for beauty. New York: Routledge.

Somerville, M. (2006). The ethical imagination: Journeys of the human spirit. Toronto: House of Anansi Press.

Van Boeckel, J. (2009). Arts-based environmental education and the ecological crisis: Between opening the senses and coping with psychic numbing. In B. Drillsma-Milgrom \& L.

Kirstina (eds.) Metamorphoses in children's literature and culture (pp. 145-164).

Turku, Finland: Enostone.

Van Boeckel, J. (2011). When we find meaning in art, our thinking is most in sync with nature: A review of 'An Ecology of Mind' - the Gregory Bateson Documentary. Retrieved from: http://www.naturearteducation.org/R/Articles.htm.

' Kant's ideas as expressed in The Critique of Judgement were initially applied to the aesthetic enjoyment of nature, though he later recognized that similar underlying grounds, with regard to aesthetic response, apply also to art.

ii Elliot Eisner (2002) examines the difference between knowledge (a noun) and knowledge (a verb) and how the arts, in many respects, are more about the latter. 